\title{
Tracheoesophageal Provox Prosthesis for Postlaryngectomy Voice Rehabilitation
}

\author{
Dr. Omar Mohammad Shafi ${ }^{1}$, Dr. Aamir Yousuf ${ }^{2}$, Dr. Ihsan Ali $^{3}$, Prof. Rauf Ahmad ${ }^{4}$
}

\begin{abstract}
Aims: Advanced cancers of larynx and hypopharynx often require total laryngectomy whichleft the patient with severe physical and functional changes that compromise someof the most vital functions, including speech communication. Voice restoration aftertotal laryngectomy has a functional importance for patient and a therapeuticchallenge for the surgeon and speech pathologist. Tracheoesophageal puncture primary or secondary and insertion of provox prosthesis for voice rehabilitation hasgained much popularity in present era due to its superior design and indwelling in nature. The purpose of the present study was to determinate the success rate and the long-term results of provox prosthesis for speech rehabilitation in our population, andimprovement in self-reported QOL among study group. Methods: Retrospective evaluation of all the patients who underwent laryngectomy with or without provox prosthesis implantation was done in SMHS hospital, a tertiary care centre of Kashmir India, the only otolaryngologist referral institute between Jan 2006to dec 2015. Results: A total of 56 patients were retrospectively evaluated, predominantly males (98\%) witha mean age of 67.5 years. $80 \%$ of the patients underwent primary and $20 \%$ secondary TEP. $78 \%$ of patients achieved functional tracheoesophageal speech, the mean device lifetime was 36 months for voice prosthesis. Prosthesis-relatedcomplications occurred in $81 \%$ of the patients and the most 32 common issues were periprosthesis leakage (26\%) and displacement (12\%). Conclusion: Our success rate of voice rehabilitation was comparable to that reported in published literature with a satisfactory better device lifetime. Because of its safety and simplicity, tracheoesophageal puncture is considered to be an effective method for voice rehabilitation after total laryngectomy.
\end{abstract}

Keywords: Tracheoesophageal puncture, provox, laryngeal cancer, postlaryngectomy rehabliltation, quality of voice .

\section{Introduction}

Language expressed through speech is a fundamental characteristic of human communication. Laryngectomy leaves patients without their natural voice. Voice restoration following total laryngectomy is an important and challenging goal for head and neck surgeons and speech pathologists. Throughout the last century, a wide variety of voice restoration have been developed and used with varying degrees of success. Although voice rehabilitation has been mainly achieved using esophageal or electrolarynx speech, nowadays prosthetic voice yields the best results. In 1980 Singer and Blom published the results of a study using their voice prosthesis inserted with an endoscopic procedure. Since then many laryngectomized patients have experienced a better quality of life. The development of the Provox voice prosthesis in 1990 at the Netherlands Cancer Institute and its further modifications in design, Provox 2 (Hilgers et al 1997) [1], has solved many of the drawbacks of the earlier prostheses and has replaced the previous methods of voice rehabilitation. The indwelling nature of the prosthesis which avoids the need for periodic removal of the prosthesis for cleaning and the wider diameter of the lumen resulting in lowered resistance to speech has resulted in greater acceptability by the patients. The technique of both primary and secondary insertion of the Provox prosthesis has been well described by Hilgers and Schouwenburg [1,2].

\section{Materials and Methods}

The study was conducted in only ENT tertiary centre of GMC, SMHS hospital, University Of Kashmir, India. The data was collected from all the patients who were following the Centre over 10 year period (Jan 2006 to dec 2015), with diagnosis laryngeal carcinoma and have undergone total laryngectomies with primary or secondary TEP(Tracheosophageal prosthesis) implantation. Total of 56 patients were registered and out of 6 patients lost their followup, and only 50 were considered for study and analyzed for quality of life with provox prosthesis on long term follow-up. Out of 50 patients primary TEP with provox prosthesis implantation was done 40 and secondary TEP with provox prosthesis implantation in 10 patients at varying intervals of time after their laryngectomy. All the 50 laryngrectomies were done for stage III/IV carcinoma of larynx. Speech practice was started following removal of the Ryle's tube and commencement of oral diet in the primary cases and the very next day after insertion in the secondary cases. Most patients were able to develop satisfactory speech within 2-3 days of speech practice. A $6 \mathrm{~mm}$ provox prosthesis was used in a majority of patients. Quality of life and voice was assessed by simple questionare to a patient in local language and intrepeted as poor,good or excellent.

\section{Results}

During the study period of 10 years more than 56 patients were registered for laryngeal carcinomas with total laryngectomies and TEP provox implantation $\mathrm{n}$ in 6 follow up was lost and only 50 patients were considered. Age of patients ranged from 40 to 70 years, 49 were males only one female patient. primary provox insertion in 40 and secondary in 10 In case of secondary TEP insertion cases were radition failure layngectomy or prosthesis couldn't be made available at time of surgery, done at interval more than 6 months. The duration of follow up ranged from 1 year to 5 years for all patients.39 patients developed loud and comprehensible voice

Volume 5 Issue 6, June 2016 


\section{International Journal of Science and Research (IJSR) \\ ISSN (Online): 2319-7064 \\ Index Copernicus Value (2013): 6.14 | Impact Factor (2015): 6.391}

and in 2 cases prosthesis was dislodged at varied interval of time 3 months in one and after 6 months in another due to postoperative radiotherapy necrosis. In 7 patients quality of speech developed was poor and they couldn't not use the prosthesis properly due to poor follow up with speech therapist, in two cases TEP is non-functional. The mean life span of provox prosthesis in our patients was 3 years with shortest being 3 months and longest one 10 years. The usual complication noted was periprosthesis leak in $20 \%$ of patients that was managed conservatively and in $12 \%$ of patients displacement prosthesis was seen. 7 patients died in follow up period.

\section{Discussion}

Advanced cancers of larynx and hypopharynx often require total laryngectomy which left the patient with severe physical and functional changes that compromise some of the most vital functions, including speech communication. Voice restoration after total laryngectomy has a functional importance for patient and a therapeutic challenge for the surgeon and speech pathologist.Tracheoesophageal puncture primary or secondary and insertion of provox prosthesis for voice rehabilitation has gained much popularity in present era due to its superior design and indwelling in nature. The present study is first of its kind in our population where laryngeal carcinomas are surprisingly rising in numbers day by day [2, 3]. The decade long follow up and assessment of success long term results and improvement in quality of voice done in study group. Among the available methods for voice restoration, tracheoesophageal prosthesis speech has shown to offer the best results in terms of quality of speech. There was no case of accidental dislodgement and in general patients were quite satisfied with the quality of speech and the prosthesis was not a hindrance to their activities. The quality of speech was found to be somewhat better. In general, patients are encouraged to have primary insertions at the time of laryngectomy itself that showed better results in terms of quality of voice probably because of primary direct dependence on prosthesis [4].The great advantage of the technique is that patients are speaking and communicating approximately the third postoperative week. TEP is a relatively simple surgical procedure and the speech is achieved rapidly. Only in cases where patients have received radical dose of radiation in the recent past (within 6 months) is secondary insertion advised, due to the risk of post-operative fistula and tracheastomal problems. The average life span of the prosthesis as per the original authors is 235 days (Hilgers et al 1993) $[1,2,5]$. In our study lifespan was seen somewhat better than seen in similar other studies with average being app 3 years longest being seen in patient using from 10 years. Our data confirm the results of other investigators that TEP for voice restoration in postlaryngectomy patients is an effective and safe technique and that the quality of speech was the good for patients underwent primarily than secondary insertion technique. Thus, we strongly recommend in our patients TEP with prosthesis insertion as the procedure of choice for restoration of voice after total laryngectomy primarily. Esophageal and other methods of speech are effective alternatives. The complication rates of this procedure are low and are not much affected by administration of radiation or chemoradiation or older patient age.

\section{References}

[1] Attieh AY, Searl J, Shahaltough NH, Wreikat MM, Lundy DS. Voice restoration following total laryngectomy by tracheoesophageal prosthesis : Effect on patients' quality of life and voice handicap in Jordan. 2008; 10:1-10.

[2] Mastronikolis NS, Stathas T, Papadas TA, Spyropoulos K, Naxakis S, Goumas D. Voice restoration after total laryngectomy using provox 2 (generation II ) prosthesis. 2008; 2(generation II):327-30.

[3] Medi- A, Sur- N. A Decade of Postlaryngectomy Vocal Rehabilitation in 318 Patients. 2000; 126:1320-8.

[4] Lopez Mj, Kraybill W, McelroyTh, Guerra O.Voice rehabilitation practices among head andneck surgeons. Ann OtolRhinolLaryngol 1987;96: 261-263

[5] Provox V, Our P, Ramalingam CW, Col L, Retd DC, Rajagopal MGG. Tracheo-esophageal Puncture (TEP) for Voice Rehabilitation in Laryngectomised Patients Blomsinger Vs Provox Prosthesis : Our Experience. 2006;

\section{Tables}

Table 1: Demographic Distribution

\begin{tabular}{|l|c|}
\hline Age yrs & AGE range /mean (67.5) \\
\hline Male & 49 \\
\hline Female & 1 \\
\hline Rural & 30 \\
\hline Urban & 20 \\
\hline Risk factor & \\
\hline Smoking & 43 \\
\hline Alcohol & 0 \\
\hline
\end{tabular}

Table 2: Methods of Prosthesis Insertion

\begin{tabular}{|l|l|l|l|}
\hline Method & No. & Quality of Voice & Number \\
\hline Primary TEP & $40(80 \%)$ & Excellent & 28 \\
\hline & & Good & 09 \\
\hline & & Poor & 03 \\
\hline Secondary TEP & $10(20 \%)$ & Excellent & 07 \\
\hline & & Good & 01 \\
\hline & & Poor & 01 \\
\hline
\end{tabular}

Figure Legend

Volume 5 Issue 6, June 2016 www.ijsr.net 


\section{International Journal of Science and Research (IJSR)}

ISSN (Online): 2319-7064

Index Copernicus Value (2013): 6.14 | Impact Factor (2015): 6.391
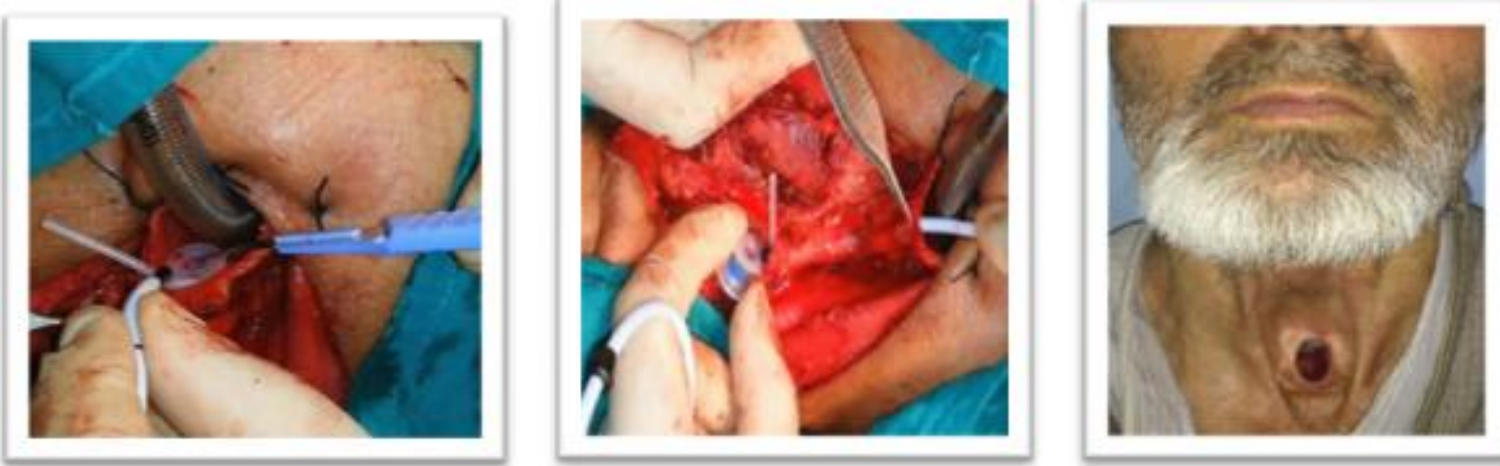

Figure 1: Implanting Provox Prosthesis

Questionnaire: Please mark a circle at the point most closely resembles your answer

\begin{tabular}{|l|l|l|l|}
\hline 1. My speech is: & Poor & Good & Excellent \\
\hline 2. Are you satisfied with your method of speech? & Unsatisfied & Satisfied & Extremely satisfied \\
\hline 3. My communication with other people is: & Poor & Good & Excellent \\
\hline
\end{tabular}

Volume 5 Issue 6, June 2016 www.ijsr.net 